\title{
Development of a Method to Measure the Quality of Working Life Using the Improved Metaheuristic Grasshopper Optimization Algorithm
}

\author{
Alireza Jafari Doudaran, Rouzbeh Ghousi $(\mathbb{D}$, Ahmad Makui, and Mostafa Jafari \\ School of Industrial Engineering, Iran University of Science \& Technology, Tehran, Iran \\ Correspondence should be addressed to Rouzbeh Ghousi; ghousi@iust.ac.ir
}

Received 28 June 2021; Accepted 26 August 2021; Published 14 September 2021

Academic Editor: Alireza Goli

Copyright ( $\odot 2021$ Alireza Jafari Doudaran et al. This is an open access article distributed under the Creative Commons Attribution License, which permits unrestricted use, distribution, and reproduction in any medium, provided the original work is properly cited.

\begin{abstract}
This paper provides a method to numerically measure the quality of working life based on the reduction of human resource risks. It is conducted through the improved metaheuristic grasshopper optimization algorithm in two phases. First, a go-to study is carried out to identify the relationship between quality of working life and human resource risks in the capital market and to obtain the factors from quality of working life which reduce the risks. Then, a method is presented for the numerical measurement of these factors using a fuzzy inference system based on an adaptive neural network and a new hybrid method called the improved grasshopper optimization algorithm. This algorithm consists of the grasshopper optimization algorithm and the bees algorithm. It is found that the newly proposed method performs better and provides more accurate results than the conventional one.
\end{abstract}

\section{Introduction}

Working life keeps changing like any other environmental condition of human life in today's world. To ensure survival in this turbulent environment, organizations and employees have no chance but to adapt to the working environment changes, which will not happen unless the quality of working life (QWL) is improved. Focusing on the improvement of the working-life quality leads to increased employee vitality and satisfaction and, in turn, the success of employees, organizations, and stakeholders [1]. Since the satisfaction of employees affects their physical conditions and mental health, organizations need to keep their employees satisfied in terms of both the work environment and the work itself, thus accomplishing the intended goals [2]. Previous studies have shown that employees with good mental health are more committed and efficient than those in low spirits [3]. Therefore, the quality of working life reflects organizational or management culture, based on which employees can experience being self-directed, responsible, and selfesteemed. In this regard, an organization's effectiveness and efficiency can be enhanced if it provides opportunities for the employees to progress [4].

Furthermore, human resources are increasingly viewed as capital [5]. Accordingly, the viability and profitability of organizations in today's turbulent situation largely depend on their ability to cope with the rapid changes in the environment and utilize the created opportunities [6]. This is possible only by the use of enterprise risk management techniques, such as holistic threats and opportunities management. To increase the value for stakeholders in the short or long term, the organization provides funds and supervises its risks by managing the market value, controlling and utilizing any possible source [7]. From an organizational perspective, the accepted definitions of risk often refer to adverse outcomes caused by an unpredictable event in the business environment [8]. There are other opinions such that risk has variable consequences, i.e., sometimes positive and sometimes negative [9]. In a general definition, human resource risks refer to the set of risks associated with the programs and processes in the human resource of an organization [10]. Ernest \& Young Institute 
considers the risks in employee-related plans and processes as the risks in human resources that, if properly managed, will make the organization one of the market leaders [11].

\section{Literature Review}

Previous studies on the quality of working life mainly measured QWL based on the level of need satisfaction [12]. For example, investigations were conducted on the relationship between QWL and job satisfaction [13] and the relationship between QWL and the organizational commitment among the lecturers in a Malaysian public research university [14]. One can also refer to the reports on QWL in child protection in two work environments [15], QWL amongst the workers of state-owned commercial banks in a Bangladesh northern region [16], QWL and the mental health of primary care physicians [17], QWL with an emphasis on human resource interventions in health units [18], QWL and the related factors for migrating workers in Guangdong Province, China [19], the effect of income and the relationship between leadership style and QWL [20] as well as QWL and burnout among nurses in critical care sections [21], quality of work life and contribution to productivity: assessing the moderator effects of burnout syndrome [22], quality of work life among young medical doctors [23], the effect of quality of work life (QWL) on job satisfaction and organization citizenship behavior [24], and determinants of quality of work life among nurses working [25].

There are also numerous studies on human resource risks such as investigations on substitution plans in New York State [10], risk perspective in human resources management [9], human resource risk management using the normal accident theory [26], and the impact of perceived human resource risk factors on financial problems [27]. According to the literature, the studies ever conducted in the field are either on quality of working life or on human resource risks. There is little research to examine these two issues together and their mutual effects. Accordingly, the present research seeks to propose a method of evaluating quality of working life on the basis of human resource risk reduction so as to enhance the quality of working life. It is to be noted that this type of study has never been carried out in the capital market. Therefore, in this study, a hybrid system is modelled to measure and improve working life quality based on the reduction of human resource risks.

\section{Methodology}

3.1. Framework. Using the tenets of previous studies, primary conceptual model has been made.

As shown in Figure 1, this model presents the various indicators widely reported, as in [28-31], for human resource risks. There are 11 categories of indicators identified to cover almost all human resource risks. Also to evaluate the quality of working life, Walton model [32] serves as a tool.

First of all, the conceptual model of the research (Figure 1) served as a basis to identify and investigate the factors that affect working life quality and human resource risks.
Then, the effect of that quality on those risks was evaluated and the factors which could reduce the risks were identified. Finally, a method was proposed to numerically measure these factors.

The data used in this study were divided into training and testing categories. For the training part, questionnaires were collected from the experts, and the data were checked by the specialists. The training phase began according to the scores given by the experts and specialists. To improve the QWL model and analyze it, the adaptive neurofuzzy inference system (ANFIS) method was used. The rules of a fuzzy inference system are based on the "if-then" set, which forms the core of the system. Once the rules are put into practice, the relationship between input and output variables can be identified. This system can be used as a forecasting model in conditions where the input or output data are highly uncertain. The basis of this approach is a set of fuzzy inference system (FIS) input and output [33].

The statistical population of this study comprised the employees of the financial institutes in the Iranian capital market. In this regard, references were made to investing companies, investment funds, investment consulting centers, and the share market for securities in Tehran. Some of the experts in these institutes were randomly selected to provide the required data.

The steps of this research, as shown in Figure 2, are as follows:

(i) Conduction of measurements and the achievement of more precise and reliable results using the improved grasshopper optimization algorithm

(ii) Evaluation of the results and the use of the grasshopper optimization algorithm combined with the bees algorithm

(iii) Introduction of a measurement system by means of the neurofuzzy inference system

(iv) Identification of the factors affecting working life quality and human resource risks through a questionnaire and confirmatory factor analysis

(v) Exploration of the relationship between working life quality and human resource risks through a questionnaire and the structural equation modelling technique

3.2. Adaptive Neurofuzzy Inference System. In this paper, the rules for training a triangular membership network are examined. The network has three membership functions, and there are two membership functions for each input. In order to model the neural-fuzzy system, the data were segmented. The segmentation was, indeed, done to train and validate the system. Eighty percent of the data was taken into account as the training data, while the remaining twenty percent was used for testing and validation. The program was then executed based on the code generated in the MATLAB software and through the method already mentioned.

As shown in Figure 3, since the factors in the chain continuity framework were composed of one main layer and 


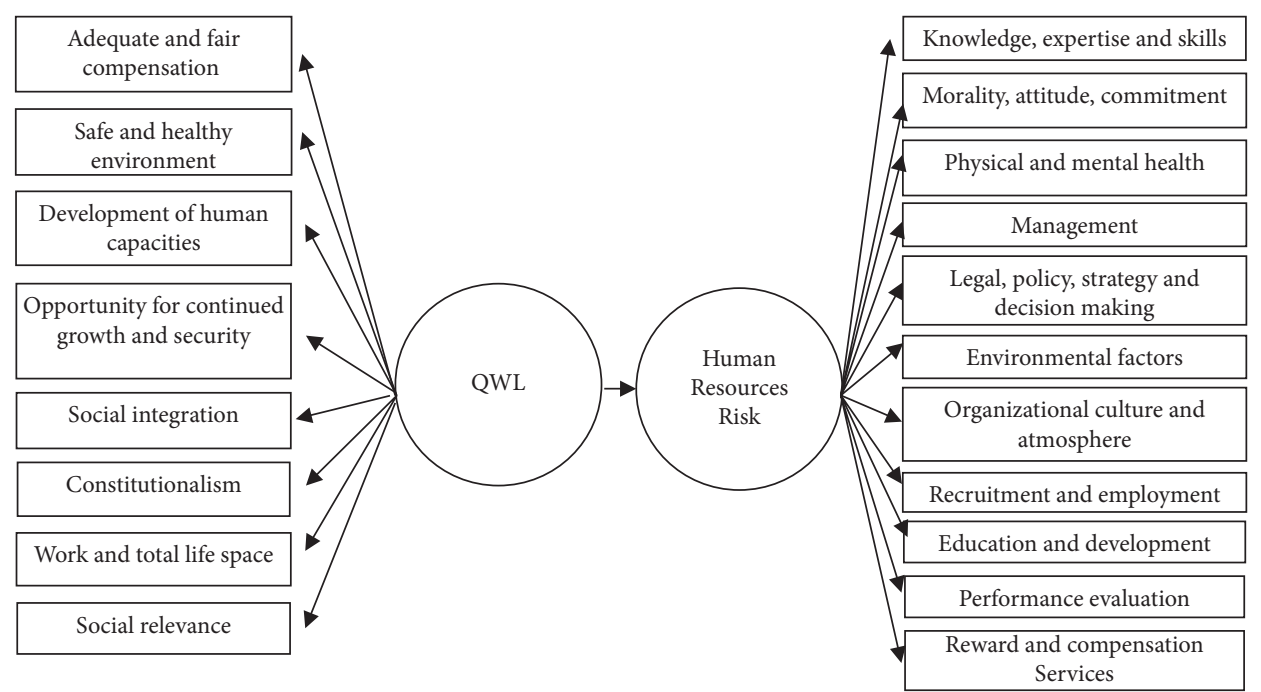

Figure 1: Conceptual research model.

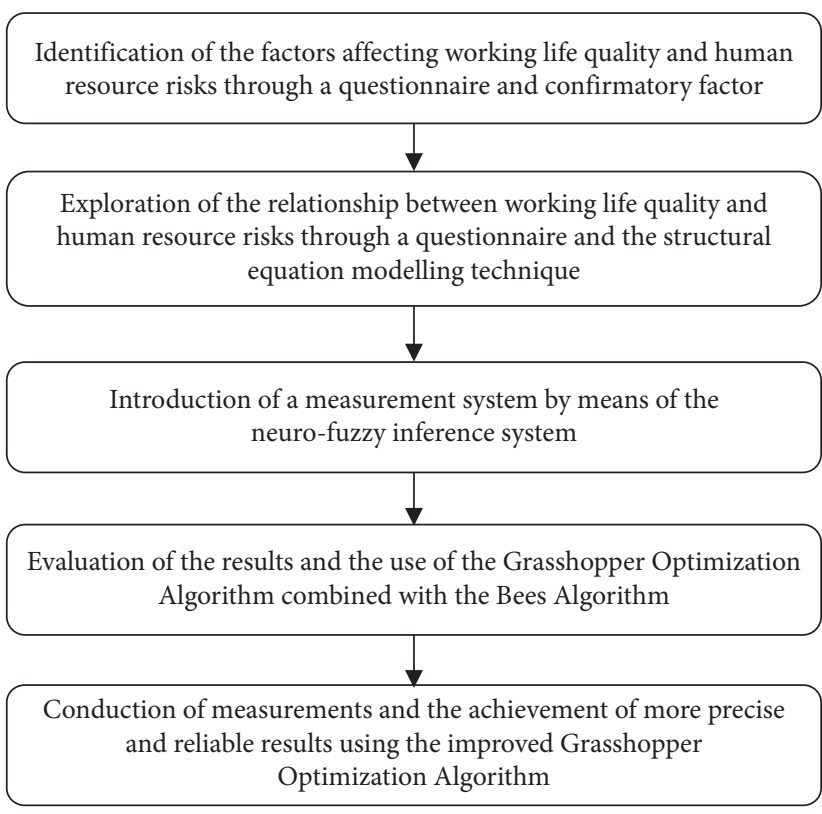

FIgURE 2: Flowchart of this research steps.

several sublayers, the neural-fuzzy inference system was modelled according to the number of the layers. At the end of the modelling phase, there were 8 neural-fuzzy systems.

\subsection{Grasshopper Optimization Algorithm (GOA).} Grasshopper optimization algorithm (GOA) is a metaheuristic algorithm inspired by nature. It mimics and simulates grasshoppers' behavior and their group movement toward food sources in nature. In order to solve an optimization problem, a GOA mathematical model is of benefit with its ability to mimic grasshoppers' behavior in nature [34]. Simulations have shown that, in comparison with the latest well-known algorithms, GOA can provide better results. Putting simulation results into practice has proven that

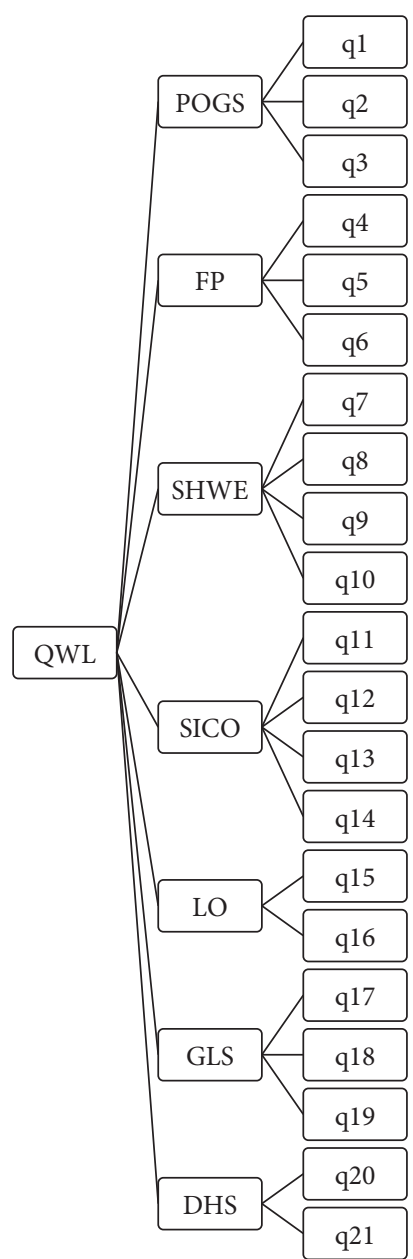

Figure 3: Structure of the layers in the adaptive neurofuzzy inference system.

GOA is capable of solving real problems with unknown space. The mathematical model used to simulate grasshoppers' behavior is as follows [35]: 


$$
X_{i}=S_{i}+G_{i}+A_{i}
$$

where $X_{i}$ is the position of grasshopper number $i, S_{i}$ is the social interaction, $G_{i}$ is the gravitational force, and $A_{i}$ is the wind flow rate.

To present a random behavior, the equation can be written as follows [36]:

$$
X_{i}=r_{1} S_{i}+r_{2} G_{i}+r_{3} A_{i},
$$

where $r_{1}, r_{2}, r_{3}$ are the random numbers in $[0,1]$.

In the above equation, $d_{i j}$ is the distance between grasshoppers $i$ and $j$, which can be calculated as $d_{i j}=\left|X_{i}-X_{j}\right|$. Moreover, $S$ function, which stands for social interaction, can be obtained using the following equation:

$$
S_{i}=\sum_{\substack{j=1 \\ j \neq i}}^{N} s\left(d_{i j}\right) d_{i j}^{\wedge},
$$

where $G_{i}$ can also be calculated as $G_{i}=-g \hat{e}_{g}$, in which $e^{\wedge} g$ is a unit vector that tends to the center of the earth.

Finally, $A_{i}$ follows the equation below, where $u$ is a fixed drift and $e^{\wedge} w$ is a wind flow unit vector:

$$
A_{i}=u \hat{e}_{w}
$$

In general, according to the equations presented, the mathematical model used to simulate the grasshoppers' behavior is as follows:

$$
X_{i}=\sum_{\substack{j=1 \\ j \neq i}}^{N} s\left(\left|x_{j}-x_{i}\right|\right) \frac{x_{j}-x_{i}}{d_{i j}}-g \hat{e}_{g}+u \hat{e}_{w} .
$$

In order to solve optimization problems, a modified version of this equation is presented as follows [37]:

$$
X_{i}^{d}=c\left[\sum_{j=1}^{N} c \frac{u b_{d}-l b_{d}}{2} s\left(\left|x_{j}^{d}-x_{i}^{d}\right|\right) \frac{x_{j}-x_{i}}{d_{i j}}\right]+\hat{T}_{d} .
$$

3.4. Bees Algorithm. In the bees algorithm, half of the bees' population is considered as workers and the other half as nonworkers. Since there is only one worker bee for each food source, the number of worker bees is equal to that of food sources around the hive. The working bees whose resources are provided by the supervising bees and the other worker bees transform into scout bees [38]. A supervisor bee selects a food source according to the probability value associated with that food source. The value is obtained from the following equation:

$$
p_{i}=\frac{\text { fit }}{\sum_{n=1}^{\mathrm{SN}} \mathrm{fit}_{n}}
$$

where $p_{i}$ is the probability of selecting $i$ bee, fit ${ }_{i}$ is the eligibility rate of $i$ solution, and $\mathrm{SN}$ is the number of food sources.

In this algorithm, the worker bees share their information with the supervisor bees, and then the supervisor bees use this information to select a new food source around the previous one. To make this selection, the following equation is used [39]. In this equation, $X_{i}$ is the answer to $i$ optimization problem and $v_{i}$ is the new answer around the answer $x_{i}$.

$$
V_{i}=X_{i}+\phi_{i}\left(X_{i}-X_{k}\right), \quad K \in\{1.2 \ldots \ldots B N\} \& K \neq I .
$$

3.5. Improved Grasshopper Optimization Algorithm (the Recommended Method in This Research). As shown in Figure 4, one of the disadvantages of using the grasshopper optimization algorithm is the convergence of grasshoppers in multiple repetitions [37].

In this study, the GOA and bees algorithm were combined to eliminate the weak point of GOA (i.e., grasshoppers' convergence in large numbers). The resulting algorithm was used as an improved grasshopper optimization algorithm. In other words, as GOA and bees algorithm were combined, a new grasshopper was added in each repetition, which prevented convergence. Ultimately, this new algorithm led to better, more accurate and more reliable results.

\section{Results and Discussion}

4.1. Phase I (Qualitative Phase): Descriptive Results. To check whether or not the distribution of the research variables was normal, the Kolmogorov-Smirnov test was used. As a statistical hypothesis, if the test significance level was greater than 0.05 , the null hypothesis cannot be rejected. It was concluded that the distribution of the variables was not significantly different from a normal distribution. The test results are presented in Table 1.

In the next step, to identify the factors affecting the quality of working life and the human resource risks in the capital market, a confirmatory factor analysis model was employed. This model is made through a structural equation and the Smart-PLS software, which makes use of partial least squares. The data were collected through a questionnaire distributed among 38 capital market specialists selected from a statistical sample of 128 capital market employees. Considering the variables and the predicted relations, the data were fed into the Smart-PLS software for a hypothetical model. After the deletion of the unknown variables, the final model emerged as shown in Figure 5.

Figure 5 shows the final factors of QWL and human resource risks. The presented figures are the absolute values of the $t$ scores above 1.96; those at the 95\% confidence level were considered significant. To check the reliability of the model (i.e., the internal similarity between the observed variables), two indicators were used, a traditional indicator called Cronbach's alpha and a composite reliability 

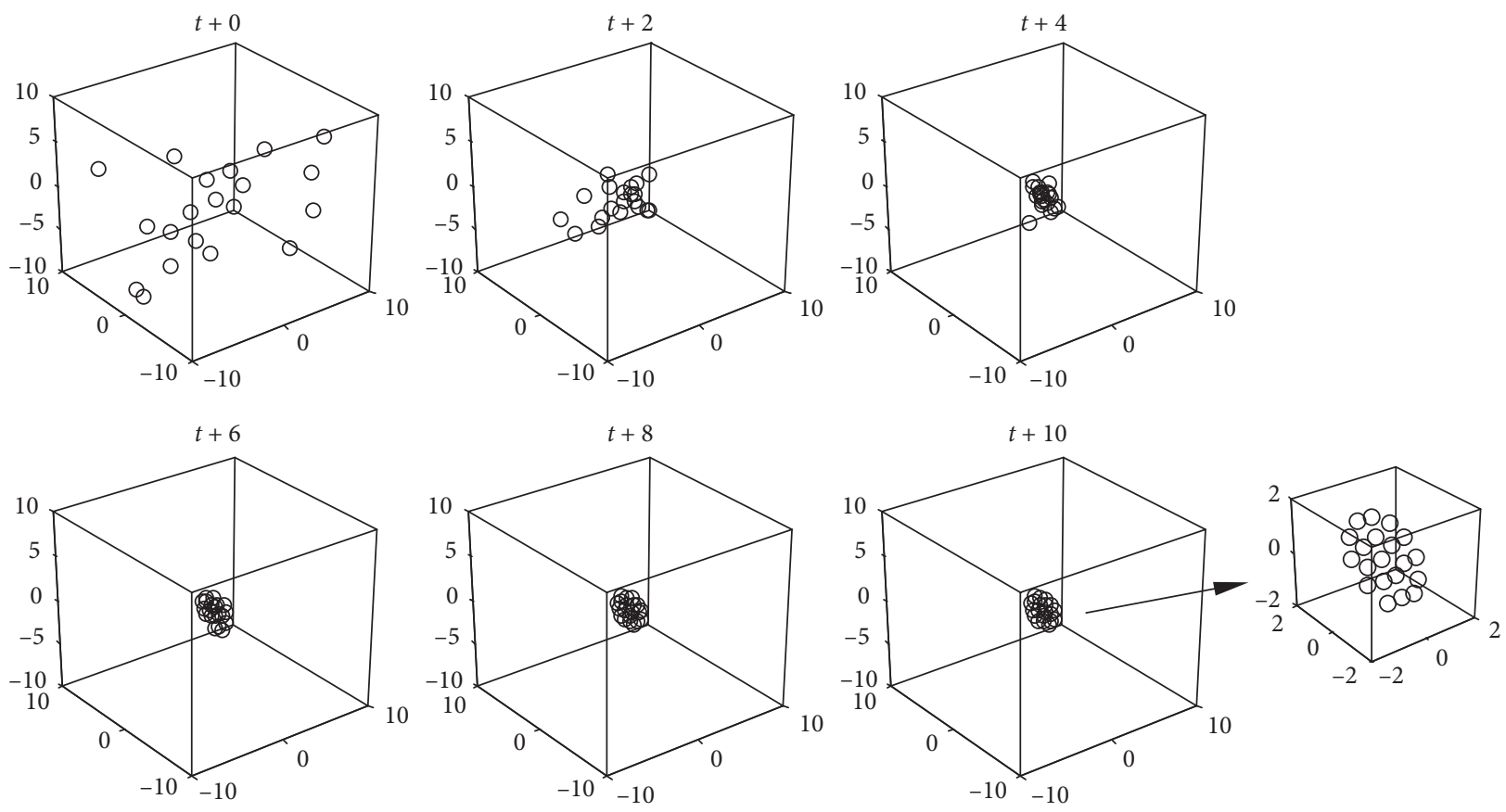

FIGURE 4: Convergence in the grasshopper optimization algorithm.

TABLE 1: Variable normality test results.

Kolmogorov-Smirnov test

Quality of working life

Variables

Adequate and fair compensation

Safe and healthy environment

Opportunity for continued growth and security

Constitutionalism

Work and total life space

Social integration

Development of human capacities

Social relevance

Human resource risks

Knowledge, expertise, and skills

Morality, attitude, and commitment

Physical and mental health

Management

Legal affairs, policy, strategy, and decision making

Environmental

Organizational culture and atmosphere

Recruitment and employment

Education and development

Performance evaluation

Reward and compensation services

\begin{tabular}{ccc}
$Z$ & Significance level & Test result \\
1.280 & 0.075 & Normal \\
1.355 & 0.051 & Normal \\
1.227 & 0.098 & Normal \\
1.351 & 0.052 & Normal \\
0.978 & 0.294 & Normal \\
0.951 & 0.327 & Normal \\
1.188 & 0.119 & Normal \\
0.988 & 0.354 & Normal \\
\hline & & \\
1.307 & 0.066 & Normal \\
1.346 & 0.054 & Normal \\
1.107 & 0.173 & Normal \\
1.136 & 0.152 & Normal \\
1.512 & 0.061 & Normal \\
1.067 & 0.205 & Normal \\
1.125 & 0,159 & Normal \\
1.096 & 0.182 & Normal \\
0.759 & 0.613 & Normal \\
0.656 & 0.782 & Normal \\
1.252 & 0.087 &
\end{tabular}

indicator. The acceptable criterion for the internal similarity of the indicators was 0.7 , which was confirmed for both models. In order to check the validity, the AVE square root of each structure was compared with the correlation values between the structures. Since the coefficients of the correlation between each structure and the others were less than the AVE root square of that structure, the validity of both models was confirmed. The transverse load test and FornellLarcker test were also used to investigate the divergent validity; the output of the matrices proved the existence of divergent validity. To evaluate and prioritize the factors affecting human resource risks, it was necessary to identify them in the capital market. To this end, expert opinions were obtained by a two-section questionnaire. In the first section, the risks were scored, and the second was given to the pairwise comparisons of the RPN criteria. After the risk levels of the RPN factors were determined, the risk priority number (RPN) was used to determine the risk level of each 

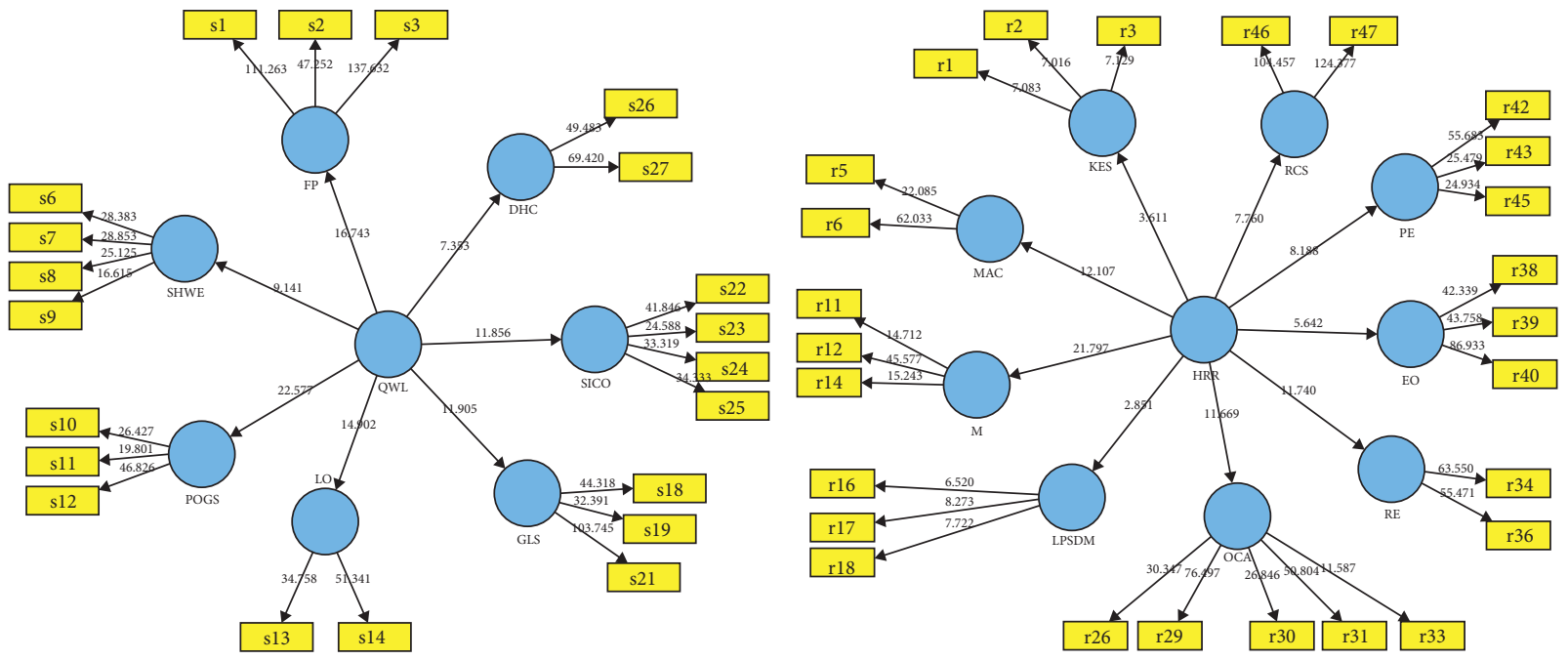

FIGURE 5: Final model of QWL and human resource risks management.

human resource risk. A RPN can be calculated using the following equation:

$$
(\mathrm{RPN}=\text { Severity } * \text { Occurance } * \text { De tection }) .
$$

As mentioned earlier, the failure modes and effects analysis (FMEA) method has several limitations for risk assessment. In this study, Fuzzy Analytical Hierarchy Process (FAHP) was implemented to address one of those limitations (considering the same importance for the RPN risk factors). To this end, in the second section of the questionnaire, the experts were asked to compare the matrices of the risk factor RPNs in a pairwise manner and state their preferences for the factors according to a fuzzy spectrum table. Then, in order to obtain the preferences of the decision-maker, a pairwise comparison of the matrices was conducted using fuzzy numbers (l. m. u). Thereafter, the obtained fuzzy values were diffused and normalized by the method of the center of gravity, and the risk factors were obtained for the RPNs.

According to Table 2, the risks of "conflict of interests in the organization, unethical behavior, and existence of lobbying culture in the organization" account for the highest RPNs, which means they are the most critical human resource risks in the capital market. On the other hand, the risks of "incompatibility of tasks with key skills and abilities of the organization's employees, failure to evaluate performance by specific criteria, and lack of proper feedback to employees" have the lowest RPNs, which means these risks are not of much importance for the capital market. To determine the RPNs of human resource risks in the capital market, the critical risks of this market need to be identified. To this end, the Pareto principle or $80-20$ rule is used. The rule asserts that $80 \%$ of outcomes (or outputs) result from $20 \%$ of all the causes (or inputs) for any given event. In other words, $20 \%$ of human resource risks cause 80 problems. Therefore, it is not necessary to examine all the risks to reduce the adverse risks. According to the Pareto principle, human resource risks are as shown in Figure 6.
As Figure 6 suggests, the risks of $r 8$ and those on its left are the ones that cause $80 \%$ of the problems. In other words, the risks that are considered critical in the Pareto principle include lack of cooperation and teamwork culture, lack of law enforcement oversight, incompatibility of training with human resources requirements, lack of up-to-date knowledge and skills in employees, wrong rules and policies, recruitment without rules or without considering the employees' qualifications, lack of human skills, poor leadership, lack of employee commitment and job abandonment, lack of managers' perceptual skills, lack of proper successor training process, low tendency to moral principles at work, lobbying culture in the organization, and unethical behavior and conflict of interests in the organization. In this study, since the Pareto principle is not proved yet, the specialists' opinions in the questionnaire were utilized to validate the results. To this end, in order to determine the risk priority number, the questionnaire also asked whether or not human resource risks were critical. In this case, the specialists' positive answers beyond the third quartile were considered as critical risks. These critical risks are shown in Table 3.

Therefore, through a correspondence made between the results obtained from the Pareto principle and those from the specialists, the commonality of the two sets of results was identified as the critical risks of human resources in the capital market. The risks are as follows:

(a) Unethical behavior (R1)

(b) Lack of managers' perceptual skills (R2)

(c) Poor leadership (R3)

(d) Wrong rules and policies (R4)

(e) Conflict of interests in the organization (R5)

(f) Recruitment without rules or without considering qualifications $(R 6)$

After the identification of the factors affecting QWL and human resource risks, the QWL model was outlined for the 
TABLE 2: Risk priority numbers (RPNs) of human resource risks.

\begin{tabular}{|c|c|c|}
\hline Priority & $\mathrm{RPN}$ & Item \\
\hline 1 & 54.87 & Conflict of interests in the organization \\
\hline 2 & 54.24 & Unethical behavior \\
\hline 3 & 47.99 & Lobbying culture in the organization \\
\hline 4 & 44.33 & Low tendency for moral principles at work \\
\hline 5 & 37.90 & Lack of proper successor training process \\
\hline 6 & 33.27 & Lack of managers' perceptual skills \\
\hline 7 & 30.78 & Lack of employee commitment and job abandonment \\
\hline 8 & 30.66 & Poor leadership \\
\hline 9 & 29.22 & Lack of human skills \\
\hline 10 & 29.19 & Recruitment without rules \\
\hline 11 & 28.54 & Wrong rules and policies \\
\hline 12 & 25.05 & Lack of up-to-date knowledge and skills in employees \\
\hline 13 & 21.75 & Incompatibility of training with human resources requirements \\
\hline 14 & 21.02 & Lack of law enforcement oversight \\
\hline 15 & 20.82 & Lack of cooperation and teamwork culture \\
\hline 16 & 19.96 & Improper and inappropriate relationship between colleagues and managers \\
\hline 17 & 19.34 & Lack of information management \\
\hline 18 & 15.03 & Lack of trust in human resources units \\
\hline 19 & 14.29 & Lack of proper procedures for identifying, developing, and retaining talented people \\
\hline 20 & 13.03 & Noncompliance with routine laws \\
\hline 21 & 12.53 & Lack of job description and appropriate structure \\
\hline 22 & 10.18 & Inadequate payment scales compared to similar organizations \\
\hline 23 & 9.67 & Employees' lack of knowledge and skill in the main activity fields of the organization \\
\hline 24 & 8.16 & Incompatibility of tasks with the key skills and abilities of the employees \\
\hline 25 & 7.80 & Failure to evaluate performance by specific criteria \\
\hline 26 & 6.91 & Lack of proper feedback to employees \\
\hline
\end{tabular}

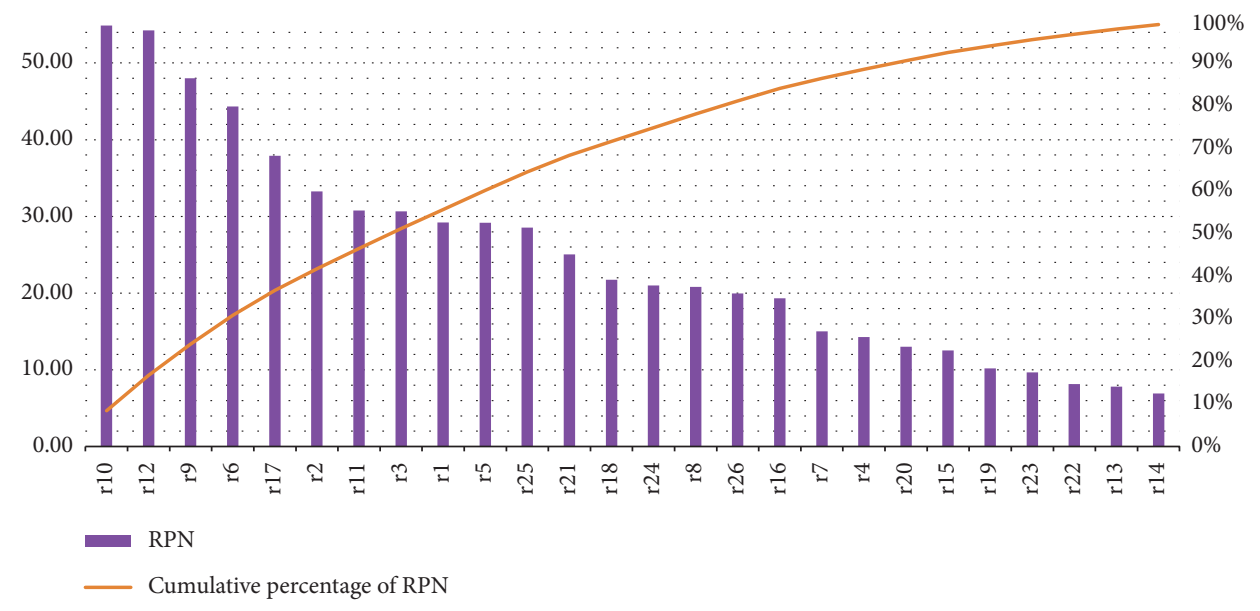

FIgURE 6: Pareto diagram of human resources risk priority number.

TABle 3: Critical risks asked about in the questionnaire.

\begin{tabular}{lcc}
\hline Item & \% support & Critical \\
\hline Lack of managers' perceptual skills & 76 & $\checkmark$ \\
Poor leadership & 87 & $\checkmark$ \\
Recruitment without rules or without considering qualifications & 79 & $\checkmark$ \\
Conflict of interests in the organization & $\checkmark 2$ & $\checkmark 9$ \\
Unethical behavior & 84 \\
Inadequate payment criteria compared to similar organizations & 79 \\
Incompatibility of tasks with the key skills and abilities of the organization's employees & 87 \\
Wrong rules and policies & $\checkmark$ & $\checkmark$ \\
\hline
\end{tabular}


reduction of the critical risks in human resources. Once the normality, validity, and reliability of the model were confirmed, at first, the relationship of QWL with human resource risks was investigated, as shown in Figure 7.

After the general model was evaluated and fitted, the quality of working life as related to human resource risks was interpreted. Based on the results gained from the test of the model, it is concluded that the model has a perfect fit. The results of the structural equation modelling, i.e., the calculated characteristics of each model path including path coefficients and $t$ values, were considered at a $5 \%$ error level, as presented in Table 4.

In the first step, to qualify the working life model on the basis of reducing the risk of human resources and investigate their relationships, a path model was implemented with the structural equation modelling technique and the Smart-PLS software. The software uses partial least squares (PLS) to provide structural equation models. This approach is less dependent on sample size than the covariance-based approach is; therefore, it can be used for small-size samples. On this basis, a hypothetical research model was introduced to the Smart-PLS software according to the predicted variables and relations. The examined model is displayed in Figure 8.

Figure 8 shows the calculated QWL model values based on reducing the risks of human resources significantly. The absolute values of the calculated quantities, if above 1.96, were considered significant at the confidence level of $95 \%$. Based on the above integrated model, the second phase of the study could start. As it can be seen in the figure above, each factor of the quality of working life had at least one significant inverse relationship with one of the critical risk factors of human resources.

4.2. Phase II (Quantitative Phase). In this section, a method was presented to determine the quality of working life based on human resource risks. First, the experts scored the items based on an available scale. The items included providing opportunities for growth and continuous security, fair payment, safe and healthy work environment, integration and cohesion in the organization, legalism in the organization, general living space, and developing human capabilities. Then, they scored the quality of working life based on the scores given to those items. After the scoring, to perform the necessary fuzzy inference process, the questionnaire data were converted from qualitative to quantitative and entered into the system. Finally, the fuzzy values had to be converted to quantitative values and go into the defuzzification process. Individual symbols were also assigned to each item for convenience, which are shown in Table 5.

The Gaussian membership functions for the POGS item and the improved grasshopper optimization algorithm (for items 1, 2, and 3 from left to right) are as follows.

As shown in Figure 9, for each of the items, 13 figures were drawn in the same way as the above figure and according to the gradient descent and improved grasshopper algorithms. Figure 9 is just one example from those 13 figures. To create a managerial perspective and quickly evaluate the impacts of the items on the categories of the quality of working life model based on the reduction of human resource risks, the influence of each item is reported in comparison to its subitems; each item has two important subitems. POGS and FP, as two example items, are presented in Figure 10.

In the next step, an adaptive fuzzy neural inference system was used to implement a decision-making assistant system for institutions and organizations operating in the capital market. The aim was to measure the quality of working life, identify the best option to improve it, and quantify its effect. The inference engine of the adaptive neurofuzzy inference system was TSK level one, the default inference engine. The number of the rules in the adaptive neurofuzzy inference system was different for each item, which can be seen in Table 6 .

In addition to the Gaussian membership function, the triangular membership function was also examined. Besides, an adaptive neurofuzzy inference system was performed based once on the gradient descent training algorithm (classic method) and once on the improved grasshopper optimization training algorithm. The results of these conductions were compared later. In order to evaluate the performance error of the employed methods, MAE, RMSE, and $R^{2}$ were used as three criteria. They are formulated as follows:

$$
\begin{aligned}
R^{2} & =\frac{\sum_{K=1}^{K} X_{k} Y_{k}}{\sqrt{\sum_{K=1}^{K} X_{k^{2}} \sum_{K=1}^{K} Y_{k^{2}}}}, \\
\mathrm{RMSE} & =\sqrt{\frac{1}{N} \sum_{t=T+1}^{T+N}\left(y_{t}^{2}-y_{t}^{\wedge 2}\right)^{2}}, \\
\mathrm{MAE} & =\frac{1}{N} \sum_{t=T+1}^{T+N}\left|y_{t}^{2}-y_{t}^{\wedge 2}\right| .
\end{aligned}
$$

In these three formulations, $N$ represents the total number of the observations done in the predicted period, $y_{t}$ and $y_{t}^{\wedge}$ denote the predicted value and the actual value at time $t$, respectively, and $X_{K}, Y_{K}$, and $K$ stand for the observational values, number of data, and estimated values, respectively.

As presented in Table 7, the adaptive neurofuzzy inference system was first implemented based on the Gaussian membership function and the gradient descent training algorithm with two and three membership functions. According to Table 8, the two criteria of MAE and RMSE from the adaptive neurofuzzy inference system with two membership functions at the values of 33.4 and 60.5 , respectively, had much poorer performance than that with three membership functions and the values of 71.3 and 63.4. In addition, the $R 2$ index of the adaptive neurofuzzy inference system with two membership functions and the value of 93.0 was smaller than that with three membership functions, which indicates the better performance of the adaptive neurofuzzy inference system with two membership functions. In general, it can be concluded that an adaptive neurofuzzy inference system with three membership 


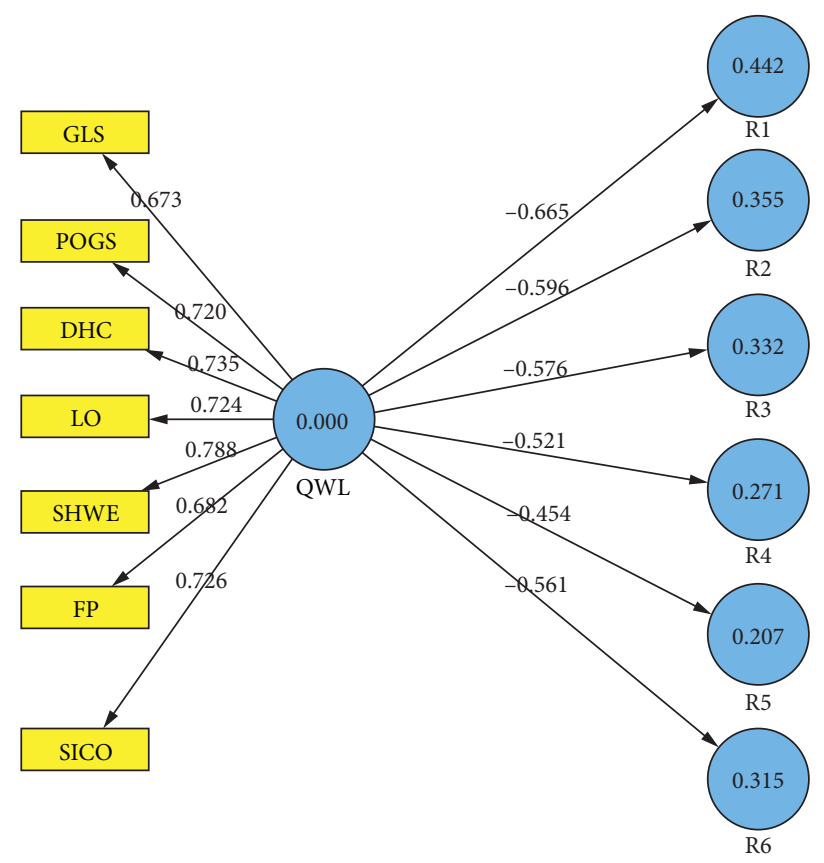

FIGURE 7: Relationship between QWL and human resource risks for the estimation of path coefficients.

TABLE 4: Results of the structural analysis of the model for the relationship between QWL and human resource risks.

\begin{tabular}{|c|c|c|c|c|c|c|c|}
\hline \multirow{2}{*}{$\begin{array}{l}\text { Independent variable } \\
\text { QWL }\end{array}$} & \multicolumn{2}{|c|}{$\begin{array}{l}\text { Dependent } \\
\text { variable }\end{array}$} & \multirow{2}{*}{$\begin{array}{c}\text { Path coefficient } \\
-0.665\end{array}$} & \multirow{2}{*}{$\frac{\text { Observed } t}{9.221}$} & \multirow{2}{*}{$\frac{\text { Critical } t}{1.96}$} & \multirow{2}{*}{$\begin{array}{c}\text { Determination coefficient }\left(R^{2}\right) \\
0.442\end{array}$} & \multirow{2}{*}{$\begin{array}{l}\text { Test result } \\
\text { Confirmed }\end{array}$} \\
\hline & $\longrightarrow$ & Risk 1 & & & & & \\
\hline QWL & $\longrightarrow$ & Risk 2 & -0.596 & 8.416 & 1.96 & 0.355 & Confirmed \\
\hline QWL & $\longrightarrow$ & Risk 3 & -0.576 & 8.562 & 1.96 & 0.332 & Confirmed \\
\hline QWL & $\longrightarrow$ & Risk 4 & -0.521 & 6.910 & 1.96 & 0.271 & Confirmed \\
\hline QWL & $\longrightarrow$ & Risk 5 & -0.454 & 6.156 & 1.96 & 0.207 & Confirmed \\
\hline QWL & $\longrightarrow$ & Risk 6 & -0.561 & 8.303 & 1.96 & 0.315 & Confirmed \\
\hline
\end{tabular}

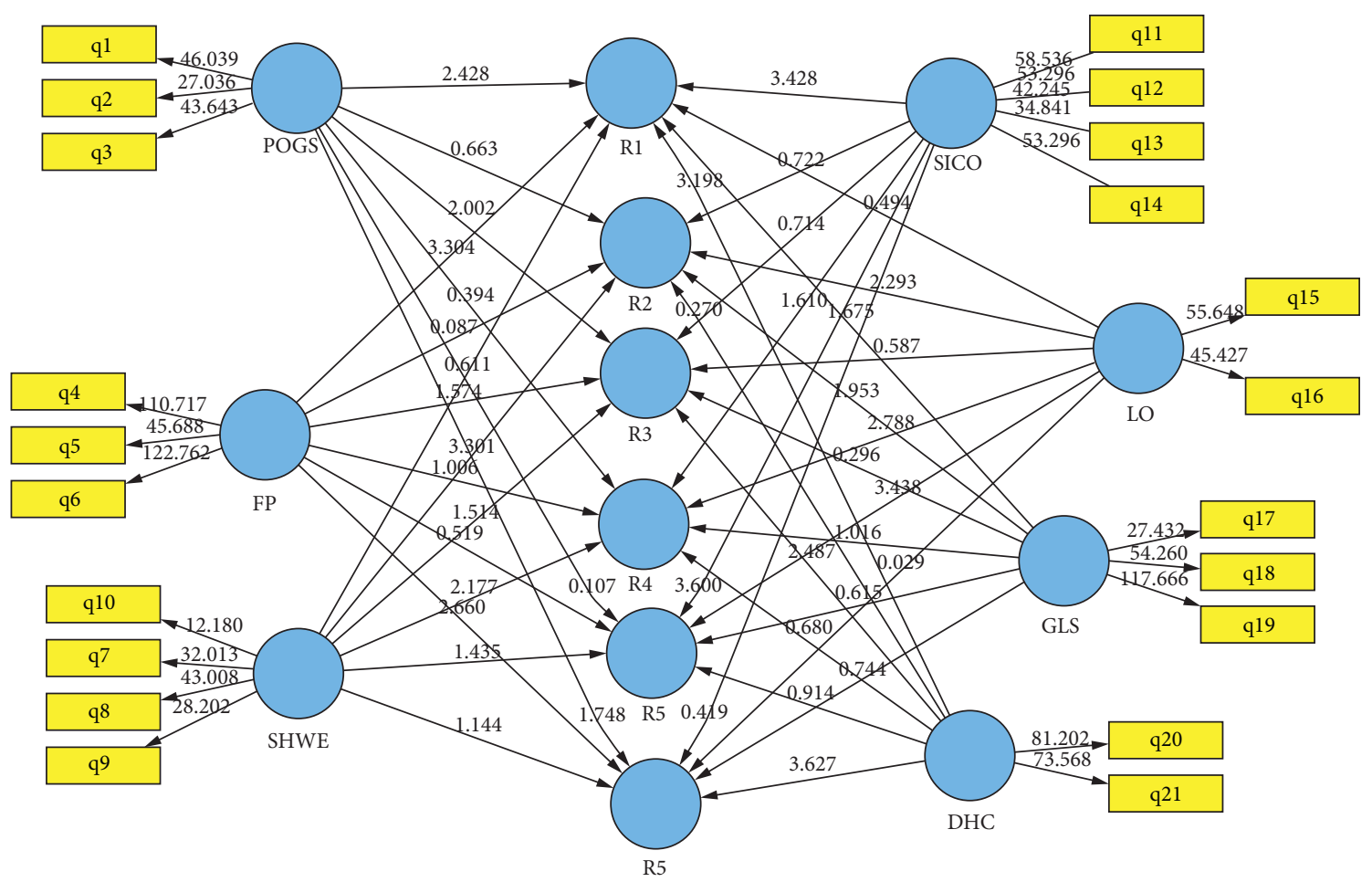

FiguRE 8: QWL path model based on the reduction of human resource risks. 
TABle 5: Symbols assigned to items.

\begin{tabular}{lcc}
\hline Row & Item & Symbol \\
\hline 1 & Opportunity for continued growth and security & POGS \\
2 & Adequate and fair compensation & FP \\
3 & Safe and healthy environment & SHWE \\
4 & Social integration & SICO \\
5 & Constitutionalism & LO \\
6 & Work and total life space & GLS \\
7 & Development of human capacities & DHC \\
8 & Quality of working life & QWL \\
\hline
\end{tabular}
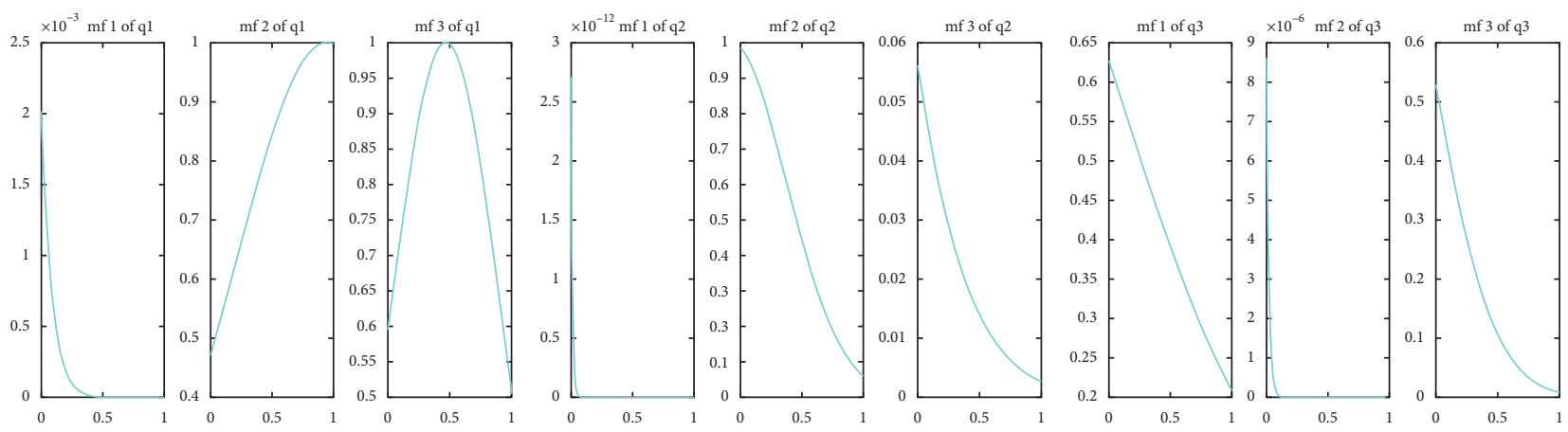

Figure 9: POGS membership functions with the gradient descent algorithm.

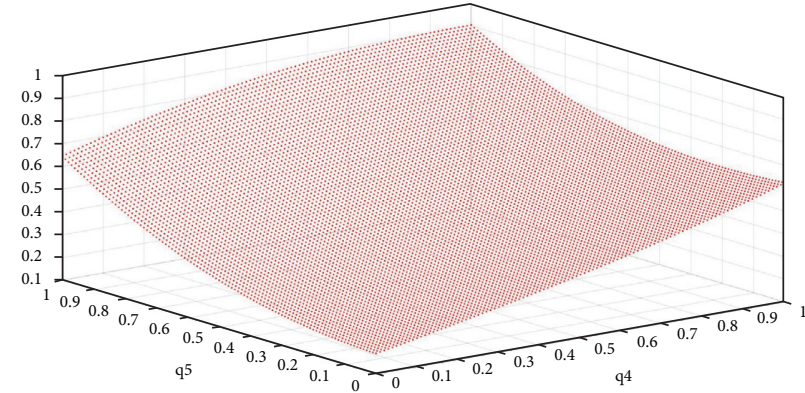

(a)

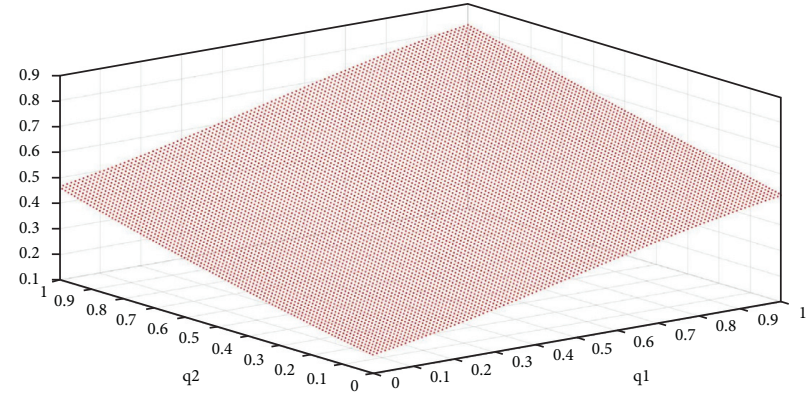

(b)

Figure 10: Procedure for the change of (b) POGS and (a) FP items from two important subitems.

TABLE 6: Number of rules in the adaptive neurofuzzy inference system.

\begin{tabular}{lccc}
\hline Row & Item & $\begin{array}{c}\text { Number of rules for two membership } \\
\text { functions }\end{array}$ & $\begin{array}{c}\text { Number of rules for three membership } \\
\text { functions }\end{array}$ \\
\hline 1 & Opportunity for continued growth and & 8 & 27 \\
2 & security & 8 & 27 \\
3 & Adequate and fair compensation & 16 & 81 \\
4 & Safe and healthy environment & 16 & 81 \\
5 & Social integration & 4 & 9 \\
6 & Constitutionalism & 8 & 27 \\
7 & Work and total life space & 4 & 9 \\
8 & Development of human capacities & 128 & 2187 \\
9 & Quality of working life & $\mathbf{1 9 2}$ & 2448 \\
\hline
\end{tabular}


TABLE 7: ANFIS results based on the Gaussian membership function and the training gradient descent algorithm with two and three membership functions.

\begin{tabular}{|c|c|c|c|c|c|c|c|c|c|}
\hline Row & $\begin{array}{l}\text { Fuzzy system } \\
\text { name }\end{array}$ & Training algorithm & $\begin{array}{l}\text { Membership function } \\
\text { type }\end{array}$ & MAE & RMSE & $R^{2}$ & $\begin{array}{l}\text { Mean } \\
\text { MAE }\end{array}$ & $\begin{array}{l}\text { Mean } \\
\text { RMSE }\end{array}$ & $\begin{array}{c}\text { Mean } \\
R^{2}\end{array}$ \\
\hline 1 & POGS & $\begin{array}{l}\text { Gradient descent } \\
\text { algorithm }\end{array}$ & Gaussian & $\begin{array}{c}3.8129^{*} \\
2.6635^{* *}\end{array}$ & $\begin{array}{l}4.5407^{*} \\
3.3045^{* *}\end{array}$ & $\begin{array}{l}0.9510^{*} \\
0.9832^{* *}\end{array}$ & $4.33^{*}$ & $5.60^{*}$ & $0.93^{*}$ \\
\hline 2 & $\mathrm{FP}$ & $\begin{array}{l}\text { Gradient descent } \\
\text { algorithm }\end{array}$ & Gaussian & $\begin{array}{c}3.7419^{*} \\
3.0903^{* *}\end{array}$ & $\begin{array}{c}5.0911^{*} \\
4.4631^{* *}\end{array}$ & $\begin{array}{c}0.9462^{*} \\
0.9440^{* *}\end{array}$ & \multirow{6}{*}{$3.71^{* *}$} & \multirow{6}{*}{$4.63^{* *}$} & \multirow{6}{*}{$0.97^{* *}$} \\
\hline 3 & SHWE & $\begin{array}{l}\text { Gradient descent } \\
\text { algorithm }\end{array}$ & Gaussian & $\begin{array}{l}4.3917^{*} \\
4.6581^{* *}\end{array}$ & $\begin{array}{c}6.1464^{*} \\
5.6852^{* *}\end{array}$ & $\begin{array}{l}0.8587^{*} \\
0.9658^{* *}\end{array}$ & & & \\
\hline 4 & SICO & $\begin{array}{l}\text { Gradient descent } \\
\text { algorithm }\end{array}$ & Gaussian & $\begin{array}{l}4.3155^{*} \\
3.0996^{* *}\end{array}$ & $\begin{array}{c}6.1249^{*} \\
3.6505^{* *}\end{array}$ & $\begin{array}{c}0.8348^{*} \\
0.9668^{* *}\end{array}$ & & & \\
\hline 5 & $\mathrm{LO}$ & $\begin{array}{l}\text { Gradient descent } \\
\text { algorithm }\end{array}$ & Gaussian & $\begin{array}{c}5.6783^{*} \\
4.1208^{* *}\end{array}$ & $\begin{array}{l}7.0991^{*} \\
4.6918^{* *}\end{array}$ & $\begin{array}{c}0.9365^{*} \\
0.9815^{* *}\end{array}$ & & & \\
\hline 6 & GLS & $\begin{array}{l}\text { Gradient descent } \\
\text { algorithm }\end{array}$ & Gaussian & $\begin{array}{l}3.5099^{*} \\
3.3579^{* *}\end{array}$ & $\begin{array}{l}4.2705^{*} \\
4.4981^{* *}\end{array}$ & $\begin{array}{c}0.9871^{*} \\
0.9750^{* *}\end{array}$ & & & \\
\hline 7 & DHC & $\begin{array}{l}\text { Gradient descent } \\
\text { algorithm }\end{array}$ & Gaussian & $\begin{array}{l}4.8871^{*} \\
4.9693^{* *}\end{array}$ & $\begin{array}{l}5.9606^{*} \\
6.1204^{* *}\end{array}$ & $\begin{array}{c}0.9729^{*} \\
0.9649^{* *}\end{array}$ & & & \\
\hline
\end{tabular}

${ }^{*}$ Data with two membership functions; ${ }^{* *}$ data with three membership functions.

TABLE 8: ANFIS results based on the Gaussian membership function and the improved GOA training algorithm with three membership functions.

\begin{tabular}{|c|c|c|c|c|c|c|c|c|}
\hline $\begin{array}{l}\text { Number of membership } \\
\text { functions }\end{array}$ & $\begin{array}{c}\text { Fuzzy system } \\
\text { name }\end{array}$ & $\begin{array}{l}\text { Training } \\
\text { algorithm }\end{array}$ & MAE & RMSE & $R^{2}$ & $\begin{array}{l}\text { Mean } \\
\text { MAE }\end{array}$ & $\begin{array}{l}\text { Mean } \\
\text { RMSE }\end{array}$ & $\begin{array}{c}\text { Mean } \\
R^{2}\end{array}$ \\
\hline 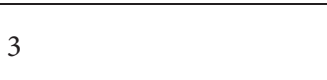 & POGS & Improved GOA & $\begin{array}{c}2.5003^{*} \\
29.1700^{* *}\end{array}$ & $\begin{array}{c}3.3981^{*} \\
38.5978^{* *}\end{array}$ & $\begin{array}{c}0.9775^{*} \\
0.0003^{* *}\end{array}$ & $3.64^{*}$ & $5.46^{*}$ & $0.92^{*}$ \\
\hline 3 & FP & Improved GOA & $\begin{array}{c}4.2157^{*} \\
13.8877^{* *}\end{array}$ & $\begin{array}{c}9.7254^{*} \\
17.0780^{* *}\end{array}$ & $\begin{array}{c}0.8272^{*} \\
0.9493^{* *}\end{array}$ & \multirow{6}{*}{$25.29^{* *}$} & \multirow{6}{*}{$31.55^{* *}$} & \multirow{6}{*}{$0.32^{* *}$} \\
\hline 3 & SHWE & Improved GOA & $\begin{array}{c}2.3944^{*} \\
49.8000^{* *}\end{array}$ & $\begin{array}{c}4.4958^{*} \\
50.8429^{* *}\end{array}$ & $\begin{array}{c}0.9208^{*} \\
0.0000^{* *}\end{array}$ & & & \\
\hline 3 & SICO & Improved GOA & $\begin{array}{c}5.4136^{*} \\
38.1959^{* *}\end{array}$ & $\begin{array}{c}6.5570^{*} \\
40.1606^{* *}\end{array}$ & $\begin{array}{c}0.8481^{*} \\
0.3187^{* *}\end{array}$ & & & \\
\hline 3 & $\mathrm{LO}$ & Improved GOA & $\begin{array}{c}2.4389^{*} \\
12.9235^{* *}\end{array}$ & $\begin{array}{c}3.1366^{*} \\
24.8688^{* *}\end{array}$ & $\begin{array}{c}0.9846^{*} \\
0.0046^{* *}\end{array}$ & & & \\
\hline 3 & GLS & Improved GOA & $\begin{array}{c}4.4709^{*} \\
19.2800^{* *}\end{array}$ & $\begin{array}{c}5.7869^{*} \\
27.6839^{* *}\end{array}$ & $\begin{array}{c}0.9756^{*} \\
0.4655^{* *}\end{array}$ & & & \\
\hline 3 & $\mathrm{DHC}$ & Improved GOA & $\begin{array}{c}4.0547^{*} \\
13.7609^{* *} \\
\end{array}$ & $\begin{array}{c}5.1343^{*} \\
21.6240^{* *} \\
\end{array}$ & $\begin{array}{c}0.9346^{*} \\
0.5081^{* *}\end{array}$ & & & \\
\hline
\end{tabular}

${ }^{*}$ Gaussian membership function data; ${ }^{* *}$ triangular membership function data.

functions performs better than the one with two membership functions. Accordingly, instead of the conventional method (i.e., gradient descent method), the improved grasshopper optimization algorithm (which is a combination of GOA and bees algorithms) was put into practice. The results gained from this improved algorithm are presented in Table 8 .

According to Tables 7 and 8, an ANFIS based on the Gaussian membership function and the improved grasshopper optimization training algorithm with three membership functions yields better results than those based on the Gaussian membership function and the gradient descent algorithm with three membership functions. It is to be noted that when the ANFIS was implemented through the improved grasshopper optimization training algorithm with a triangular membership function, as expected, it had a high error. Other membership functions, such as trapezoidal function, were abandoned due to nondifferentiability and lack of flexibility.
In general, according to the results of the second phase of the study, the use of the grasshopper optimization algorithm and its combination with the bees algorithm leads to more accurate results. Indeed, since grasshoppers' convergence in numerous repetitions is a disadvantage of using the GOA method, combining it with the bees algorithm provides more accurate and reliable results; it has been known that adding a new grasshopper at every repetition stage helps to avoid convergence.

\section{Conclusion}

Considering the gap in the literature on QWL and human resource risks and their evaluation, this study was conducted to devise a method for measuring QWL so as to reduce human resource risks in the capital market. The research was done in two phases. In the first phase, the factors affecting QWL and human resource risks as well as their mutual 
impacts were identified and studied. In the second phase, a method was provided to measure the characteristics obtained in the first phase. As the results of the first phase showed, all the identified QWL factors reduced at least one of the human resource risks. In this regard, the quality of working life was found to have the most significant impact on the reduction of the 'unethical behavior' as a risk. The unethical behavior of employees can indeed cause many problems. It can even push a business to failure. One way to cope with this problem is to pay special attention to the quality of working life and the reduction of risks in human resources. The best way to monitor a factor is to measure and display it numerically. This makes it possible to improve the plans for operation and the efficacy of the measures taken. The second phase of the study is dedicated to the method proposed for the measurement of the quality of working life in link with the risks involved in human resources. The measurements were made through the neurofuzzy inference system by means of the improved grasshopper optimization algorithm. This algorithm was a combination of the grasshopper optimization algorithm and the bees algorithm. In this respect, the results of the second phase of the research show that the proposed method to measure the quality of working life based on human resource risks is more accurate and reliable than the conventional method in the adaptive neural network (i.e., reduction gradient method). The proposed method serves to create a decision-assistant system for managers and business owners to measure the quality of working life, select the best option to improve it, and ultimately measure the feedbacks on its effectiveness numerically. Inspired by this method, capital market managers can obtain the QWL of their employees and take appropriate measures to improve it, which, in turn, leads to the reduction of risks in human resources and the growth of their business. According to the account provided in this research for the capital market, it is suggested that the issue is examined in other fields and occupations such as banking and insurance and that the results are compared with those of this research.

\section{Data Availability}

Some of the numerical data and software outputs data used to support the findings of this study are included within the article. Also this data in full are currently under embargo. But requests for data, after publication of this article, will be considered by the corresponding author.

\section{Conflicts of Interest}

The authors declare that they have no conflicts of interest.

\section{References}

[1] M. J. Almalki, G. Fitzgerald, and M. Clark, "Quality of work life among primary health care nurses in the Jazan region, Saudi Arabia: a cross-sectional study," Human Resources for Health, vol. 10, no. 1, pp. 30-13, 2012.

[2] T. A. Wright and D. G. Bonett, "Job satisfaction and psychological well-being as non additive predictors of workplace turnover," Journal of Management, vol. 33, no. 2, pp. 141-160, 2007.

[3] K. W. Chan and T. A. Wyatt, "Quality of work life: a study of employees in Shanghai, China," Asia Pacific Business Review, vol. 13, no. 4, pp. 501-517, 2007.

[4] M. Khaghanizadeh, A. Ebadi, N. M. Sirati, and M. Rahmani, "The Study of Relationship between Job Stress and Quality of Work Life of Nurses in Military Hospitals," Journal of Militery Medicine, vol. 10, no. 3, pp. 175-184, 2008.

[5] D. J. Armstrong, C. K. Riemenschneider, M. W. Allen, and M. F. Reid, "Advancement, voluntary turnover and women in IT: a cognitive study of work-family conflict," Information \& Management, vol. 44, no. 2, pp. 142-153, 2007.

[6] J. Firmenich, "Customisable framework for project risk management," Construction Innovation, vol. 17, no. 1, pp. 68-89, 2017.

[7] L. A. Gordon, M. P. Loeb, and C.-Y. Tseng, "Enterprise risk management and firm performance: a contingency perspective," Journal of Accounting and Public Policy, vol. 28, no. 4, pp. 301-327, 2009.

[8] M. Jablonowski, Precautionary Risk Management: Dealing with Catastrophic Loss Potentials in Business, the Community and Society, Springer, Berlin, Germany, 2006.

[9] K. Becker and M. Smidt, "A risk perspective on human resource management: a review and directions for future research," Human Resource Management Review, vol. 26, no. 2, pp. 149-165, 2016.

[10] A. E. Staehr, "Human resource risk and succession planning," Agricultural Finance Review, vol. 75, no. 1, pp. 133-139, 2015.

[11] Ernst \& Young, 2008 Global Human Resources (HR) Risk: From the Danger Zone to the Value Zone, EY, London, 2008.

[12] M. J. Sirgy, D. Efraty, P. Siegel, and D.-J. Lee, "A new measure of quality of work life (QWL) based on need satisfaction and spillover theories," Social Indicators Research, vol. 55, no. 3, pp. 241-302, 2001.

[13] S. Elisaveta, "Relationship among perceptions of quality of working life and job satisfaction," Management and Organization Review, vol. 2, no. 3, pp. 459-460, 2006.

[14] H. Farid, Z. Izadi, I. A. Ismail, and F. Alipour, "Relationship between quality of work life and organizational commitment among lecturers in a Malaysian public research university," The Social Science Journal, vol. 52, no. 1, pp. 54-61, 2015.

[15] B. J. Cohen, S. C. Kinnevy, and M. E. Dichter, "The quality of work life of child protective investigators: a comparison of two work environments," Children and Youth Services Review, vol. 29, no. 4, pp. 474-489, 2007.

[16] M. M. Rahman, M. R. Ali, and M. F. Islam, "A Study on quality of working life among workers with special reference to state owned commercial banks in the northern region of Bangladesh," Global Journal of Management and Business Research, vol. 14, 2014.

[17] R. González-Baltazar, G. Hidalgo-Santacruz, S. G. LeónCortés et al., "Quality of work life and mental health in primary care physicians," Procedia Manufacturing, vol. 3, pp. 4935-4940, 2015.

[18] T. Nayak, C. K. Sahoo, and P. K. Mohanty, "Impact of HR interventions on quality of work life: evidence from healthcare units," International Journal of Indian Culture and Business Management, vol. 14, no. 2, pp. 214-236, 2017.

[19] X. Tian, "QWL and related factors for migrant workers survey in Guangdong Province, China," Journal of Social Service Research, vol. 46, no. 2, pp. 160-169, 2020.

[20] D. Kara, H. L. Kim, G. Lee, and M. Uysal, "The moderating effects of gender and income between leadership and quality 
of work life (QWL)," International Journal of Contemporary Hospitality Management, vol. 30, no. 3, pp. 1419-1435, 2018.

[21] H. Huang, H. Zhang, Y. Xie et al., "Effect of balint group training on burnout and quality of work life among intensive care nurses: a randomized controlled trial," Neurology Psychiatry and Brain Research, vol. 35, pp. 16-21, 2020.

[22] J. Leitão, D. Pereira, and Â. Gonçalves, "Quality of work life and contribution to productivity: Assessing the moderator effects of burnout syndrome," International Journal of Environmental Research and Public Health, vol. 18, no. 5, p. 2425, 2021.

[23] M. Storman, D. Storman, and J. Maciąg, "Quality of work-life among young medical doctors in Poland," International Journal of Occupational Safety and Ergonomics, vol. 27, pp. 1-7, 2021.

[24] I. Ruhana, "The effect of quality of work life (QWL) on job satisfaction and organization citizenship behavior (OCB) (A study of nurse at numerous hospitals in Malang, Indonesia)," JPAS (Journal of Public Administration Studies), vol. 4, no. 2, pp. 51-58, 2020.

[25] L. Kelbiso, A. Belay, and M. Woldie, "Determinants of quality of work life among nurses working in Hawassa town public health facilities, South Ethiopia: a cross-sectional study," Nursing Research and Practice, vol. 2017, Article ID 5181676, 2017.

[26] T. S. Calvard and D. Jeske, "Developing human resource data risk management in the age of big data," International Journal of Information Management, vol. 43, pp. 159-164, 2018.

[27] J. P. Bruwer and J. P. Rossouw, "The influence of perceived human resource risk factors on financial problems faced by overberg district municipalities," Journal of Economics and Behavioral Studies, vol. 11, no. 1, pp. 48-54, 2019.

[28] M. B. Young and E. S. Hexter, Managing Human Capital Risk: A Call for Partnership between Enterprise Risk Management and Human Resources, Conference Board of Canada, Ottawa, Canada, 2011.

[29] E. Kupi, S. K. Ilomäki, V. Sillanpää, H. Talja, and A. Lönnqvist, Aineettoman Pääoman Riskienhallinta: Riskit Ja Riskienhallinnan Käytännöt Yrityksissä, 2008.

[30] J. Stevens, V. Jeynes, E. Cotena, and M. Edelson, Managing Risk: The HR Contribution, Routledge, England, UK, 2006.

[31] A. Gholipour and E. Ebrahimi, "Human resource risk management: mix method application," Management Researches, vol. 9, no. 32, pp. 73-96, 2016.

[32] R. E. Walton, "Criteria for quality of working life," in Quality of Working Life: Problems, Projects and the State of the Art, L. E. Davis, Ed., pp. 91-104, Macmillian, New York, NY, USA, 1975.

[33] E. Krueger, S. A. Prior, D. Kurtener, H. H. Rogers, and G. B. Runion, "Characterizing root distribution with adaptive neuro-fuzzy analysis," International Agrophysics, vol. 25, no. $1,2011$.

[34] A. A. Heidari, H. Faris, I. Aljarah, and S. Mirjalili, “An efficient hybrid multilayer perceptron neural network with grasshopper optimization," Soft Computing, vol. 23, no. 17, pp. 7941-7958, 2019.

[35] C. M. Topaz, A. J. Bernoff, S. Logan, and W. Toolson, "A model for rolling swarms of locusts," The European Physical Journal-Special Topics, vol. 157, no. 1, pp. 93-109, 2008.

[36] S. M. Rogers, T. Matheson, E. Despland, T. Dodgson, M. Burrows, and S. J. Simpson, "Mechanosensory-induced behavioural gregarization in the desert locust schistocerca gregaria," Journal of Experimental Biology, vol. 206, no. 22, pp. 3991-4002, 2003.
[37] S. Saremi, S. Mirjalili, and A. Lewis, "Grasshopper optimization algorithm: theory and application," Advances in Engineering Software, vol. 105, pp. 30-47, 2017.

[38] D. Karaboga and B. Basturk, "A powerful and efficient algorithm for numerical function optimization: artificial bee colony (ABC) algorithm," Journal of Global Optimization, vol. 39, no. 3, pp. 459-471, 2007.

[39] D. T. Pham, A. Ghanbarzadeh, E. Koç, S. Otri, S. Rahim, and M. Zaidi, "The bees algorithm-a novel tool for complex optimisation problems," in Intelligent Production Machines and Systems, pp. 454-459, Elsevier Science Ltd, 2006. 